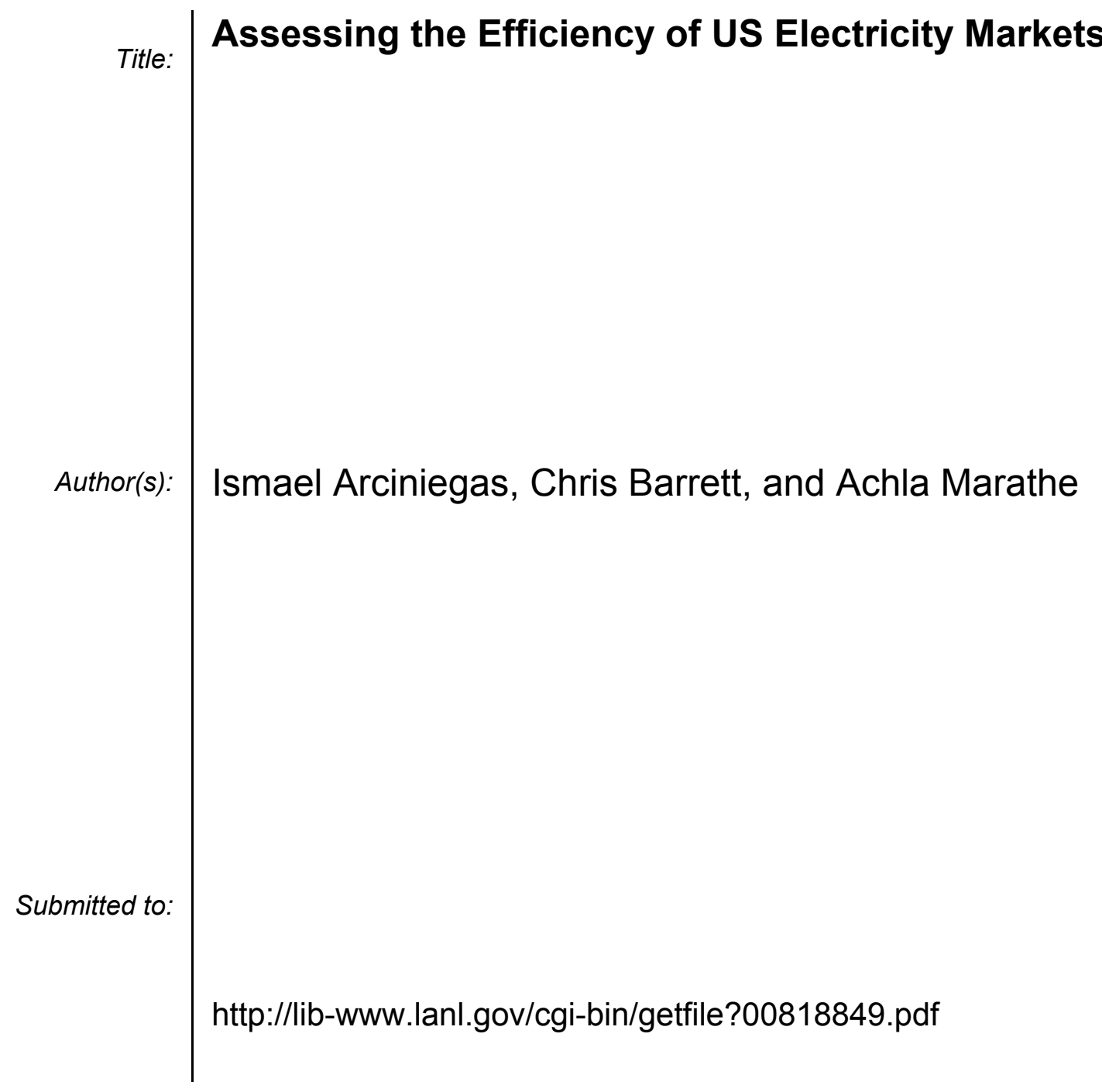

Los Alamos National Laboratory, an affirmative action/equal opportunity employer, is operated by the University of California for the U.S. Department of Energy under contract W-7405-ENG-36. By acceptance of this article, the publisher recognizes that the U.S. Government retains a nonexclusive, royaltyfree license to publish or reproduce the published form of this contribution, or to allow others to do so, for U.S. Government purposes. Los Alamos National Laboratory requests that the publisher identify this article as work performed under the auspices of the U.S. Department of Energy. Los Alamos National Laboratory strongly supports academic freedom and a researcher's right to publish; as an institution, however, the Laboratory does not endorse the viewpoint of a publication or guarantee its technical correctness. 


\title{
ASSESSING THE EFFICIENCY OF US ELECTRICITY MARKETS
}

\author{
Ismael Arciniegas ${ }^{\mathrm{a}}$ (ismaela@lanl.gov), Chris Barrett ${ }^{\mathrm{a}}$ (barrett@lanl.gov), \\ and Achla Marathe ${ }^{b, *}$ (achla@lanl.gov) \\ ${ }^{a}$ Los Alamos National Laboratory. Basic and Applied Simulation Science (D-2) \\ ${ }^{\mathrm{b}}$ Los Alamos National Laboratory. Modeling, Algorithms and Informatics Group (CCS-3) \\ ${ }^{*}$ Corresponding author: Phone: (505)667-9034, Mail Stop B265
}

\section{Abstract}

The recent California's energy crisis has raised doubts about the benefits of energy deregulation. While it is true that the California electricity market is in turmoil, other electricity markets like the Pennsylvania-New Jersey-Maryland (PJM) are doing fine. This paper assesses the mark of efficiency reached by the electricity markets in California, New York, and PJM. It also compares the degree of efficiency across markets (forward vs. real time) and across time. In terms of market efficiency no significant differences between the California and PJM electricity markets were discovered in the year of California's energy crisis (2000). This research suggests that differences in price behavior between these two markets during 2000 did not arise from differences in efficiency. According to our analysis and measure of efficiency, PJM and California electricity markets are more efficient than the New York market. Also, as these markets become more mature over time, their efficiency goes up. We also found evidence that multi-settlement scheduling system leads to higher efficiency. 


\section{Introduction}

The recent deregulation of the power industry in several parts of the United States has produced different results across states. California's deregulation has been characterized by skyrocketing wholesale electricity prices and several utilities on the brink of bankruptcy. The New York electricity market has encountered up to $30 \%$ increase in the electricity bills. On the other hand, the Pennsylvania - New Jersey - Maryland (PJM) electricity market is enjoying low energy prices. In fact, the users of this market have saved 3 billion dollars on electricity bills. The turmoil in some of the electricity markets is casting a shadow of doubt on deregulation plans of other states. A better understanding of the real causes of the differences in performance across electricity markets in the US is needed to help resolve some of the important issues.

Market inefficiency, market power, inelastic demand, and constrained supply are often quoted as the main cause of the problems experienced by some of the electricity markets (See [1]). The aim of this paper is to assess the mark of efficiency reached by the electricity markets in California, New York, and PJM and see if some of the differences in price dynamics in these markets could be explained by the difference in their level of market efficiency. To the best of our knowledge a comparative analysis of efficiency among California, New York, and PJM electricity markets is novel.

For this study hourly prices of day-ahead and real-time markets for each of the three power markets are collected. The price data was taken from the Independent System Operator's website of each market and from the University of California Energy Institute (UCEI) ${ }^{1}$. Some of the hourly price series were available by load zone and not per market. In those cases an aggregation was done using load-weighted averages. Given the data availability, a selected group

\footnotetext{
${ }^{1}$ The websites from which the data was retrieved were: www.nyiso.com, www.pjm.com, www.caiso.com, www.ucei.berkeley.edu/ucei.
} 
of years was analyzed for each market: California (1998-2000), PJM (1999-2001), and New York (2000-2001). The results indicate that efficiency has risen with the maturity of the markets. Interestingly, this research did not find significant differences in efficiency between the California and PJM power markets during the year of the California's energy crisis (2000). The New York electricity market was found to be the least efficient among the three.

\section{Comparison of California, PJM and New York electricity markets}

This study analyzes the price dynamics of the power markets in California, PJM, and New York and compares the level of efficiency reached by each one of these markets. A market is efficient when all the relevant and ascertainable information is fully and immediately reflected in market prices. In an efficient market all players are well-informed and adjust their market strategies continuously to take advantages of the arbitrage opportunities. An arbitrage opportunity exists if it is possible to design a strategy that can yield risk less economic profits (See [2] for details). There is plenty of literature that describes the functioning of California, PJM, and New York electricity markets (See [3], [4], [5], and [6]). A review of that literature points out important differences in market structure across states which may explain differences in market efficiency. Some of these differences are discussed below:

- Maturity of the market: As the market matures, players accumulate more experience which allows them to be better prepared to take advantage of the arbitrage opportunities. Removal of these arbitrage opportunities leads to higher market efficiency. Hence differences in "maturity" between markets may be relevant in explaining differences in efficiency across markets. 
California was the first US state to restructure its electricity market which started at the beginning of 1998. PJM which is the oldest centralized dispatched network in the world started its restructuring at the beginning of 1999. New York's deregulated electricity market also started operation in 1998 although it was later than California ${ }^{2}$.

- Multi-settlement vs single-settlement scheduling systems: In the scheduling process two alternatives are available: Multi-settlement and single-settlement system. Under a multisettlement system implies the prices and quantities established in market phases prior to dispatch are binding forward contracts. The spot-market (run by the ISO) is used to settle any difference between the scheduled transactions and the actual transactions. In a singlesettlement system the forward phase is used just for scheduling purpose, all transactions are settled at the spot market price (See [5] for additional details).

California runs a multi-settlement system with day-ahead and hour-ahead phases prior to dispatch. In California, the day-ahead transactions are binding and settled at the day-ahead price. Similarly, the hour-ahead transactions are settled at the hour-ahead prices. Until May 31, 2000 PJM ran a single-settlement system. On June 1, 2000 PJM switched to a multi-settlement system that is similar to the California's system. The NY electricity market has day-ahead and hour-ahead phases as well as a real-time one. Like in California these markets work in a multi-settlement system, where the transactions in the forward market (day and hour-ahead) are traded at the forward price. The balance between the real-time transactions and the scheduled ones is traded at the real-time price.

The multi and single-settlement systems have potential advantages and disadvantages which may have an impact on market efficiency. A multi-settlement system may increase the opportunities for arbitrage by running a binding day-ahead

\footnotetext{
${ }^{2}$ Information obtained from the energy information administration www.eia.doe.gov
} 
market which is repeated on an hour-ahead basis. It also reduces risk by providing price certainty to the generators before the actual dispatch (See [5]). On the other hand, a single-settlement system may lead to productive efficiency gains by lowering the transactions costs that a sequence of forward markets may produce.

- Competing forward markets: [4] argues that having competitive forward markets which can trade with one another may reduce the arbitrage opportunities existing in the electricity markets by increasing the competitive discipline in the forward markets. Thus, differences in the organization of the forward markets across states may explain differences in market efficiency.

In California, competing scheduling coordinators (SCs) run the forward markets. The Independent System Operator (ISO) runs the transmission, ancillary and real-time markets. Among the SCs, the Power Exchange (PX) used to handle most of the trading in the California forward markets ${ }^{3}$. The PX ran auctions to establish energy prices and schedules for both the day-ahead and hour-ahead market. On the other hand, the Automated Power Exchange which is also an SC, runs a continuous forward market. The others SCs in California work through bilateral contracts to tailor consumers' needs. The energy prices in the different SCs converge as trading among SCs is permitted.

In PJM the participants can implement the day-ahead phase either by submitting bids to a centralized dispatch managed by the ISO or by decentralized bilateral schedules. Unlike California, PJM has just one centralized day-ahead dispatch which is administrated by the ISO. In the ISO-run day-ahead market, generators' offers must specify the prices and the ranges of output over which these prices apply. In the bilateral scheduling, participants indicate the amount of energy injected and withdrawn from each

\footnotetext{
${ }^{3}$ The PX filed for bankruptcy at the beginning of 2001.
} 
location in each hour of the following day. The ISO uses the bids of the centralized dayahead market to run an optimization program. This determines the minimum cost order of dispatch that meets the forecasted load that is not going to be supplied by the bilateral arrangements in the next day. The results from the optimization program tell all the market participants the likelihood of selling or buying power over the next day. See [5] for more information.

Like in PJM, there are no competing centralized forward markets in New York. The centralized day-ahead dispatch is managed by the ISO which receives the bids from the market participants and produces a load forecasts for all hours of the following day. ISO runs an optimization program with the load forecast and the bids to determine the mix of generation for the next day that minimizes the production costs over the day while observing the constraints on the transmission system. The optimization program also computes the day-ahead market price.

The ISO-run day-ahead markets of PJM and New York are subject to the competitive discipline of the bilateral markets ${ }^{4}$. However, an ISO can use its power as grid manager to favor its day-ahead market undermining the fairness of the market and therefore its efficiency.

- Long-tem markets: As suggested by [6] the existence of many forums for trading over time (long-term, day-ahead, hour-ahead) encourages generators to compete more aggressively in the spot market as they have sold significant portions of their output in the forward markets. More aggressive competition should lead to faster learning and more efficiency.

\footnotetext{
${ }^{4}$ As any player can choose between submitting bids to the ISO-run day ahead market and bilateral market.
} 
Till recently, California utilities were not allowed to get into long term contracts and more than $90 \%$ of the power was purchased in the spot market. Instead in PJM, utilities could lock in prices through long term contracts. Therefore only 10 to $20 \%$ of the power was bought in the spot market. Due to the higher flexibility available in PJM to meet its long term energy needs, the prices were less volatile in PJM as compared to California.

- Ancillary services (AS): As a generator has to decide how to bid in each market, a shock in the AS market is going to be reflected in the forward and spot markets. As noted by [3] the structure of AS market greatly complicates a generator's choice in bidding in the electricity markets. More bidding choices for a generator decrease its ability to find potentially riskless strategies.

In PJM just operating reserves and regulation ${ }^{5}$ are traded. PJM assigns duties in providing regulation to all generators. If a generator can not provide regulation, it must meet its obligation by writing bilateral contracts. Till May 31 2000, PJM used a cost based market for procuring regulation but in June 2000, PJM started procuring regulation using market prices.

In California the AS markets allocate: regulation, spinning reserves, non-spinning reserves, and replacement reserves ${ }^{6}$. In California's electricity market, AS are allocated using day-ahead and hour-ahead markets. For the day-ahead AS market, a generator submits bids in which it specifies the total capacity that the ISO can use for any of the four services (regulation, spinning reserves, non-spinning reserves and replacement reserves) and the energy price (uniform for all services). Each hour the ISO examines the

\footnotetext{
${ }^{5}$ Regulation refers to the services provided by generators to maintain a $60 \mathrm{~Hz}$ operating level in the transmission network.

${ }^{6}$ The types of reserves differ by the amount of time the generator has before it must begin supplying power to the grid and whether or not the facility must be synchronized to the grid while waiting in reserve.
} 
system and determines the amount of AS it requires. The ISO resolves each market in sequence starting with regulation first and ending with reserve replacement. If a generators was not selected in the first AS it can still participate in the next AS market. The AS hour-ahead market operates similar to the AS day-ahead market. Unlike PJM, in California the generators do not bid in each one of the AS markets independently.

In New York, each one of the six AS is traded independently in the market. Suppliers receive payments according to the quantities supplied and the market clearing prices in the day-ahead and supplemental markets.

- Fuel $\mathbf{m i x}^{7}$ : The volatility of the fuel prices varies depending upon the fuel. Volatility in fuel price causes volatility in the electricity prices because fuels are a major component of generators' costs. Therefore, a diversified fuel source may prevent excess of volatility in the electricity prices. The lower volatility may lead to fewer arbitrage opportunities and more efficient and stable market.

In California most of the energy is provided by gas-fired (51\%) and hydro (26\%) generators. In contrast, PJM fuel mix is more diverse including coal, and nuclear. Like PJM, the fuel mix in New York is also more diverse than in California. NY electricity market uses gas (17.2\%), hydroelectric (23\%) and nuclear (27\%).

\section{Market efficiency}

\subsection{Related work}

Our approach to studying market efficiency in power markets is similar to previous empirical literature that focused on the price dynamics of power markets around the world. In $[7,8]$, the authors analyze the price dynamics of 11 interconnected regional markets in the

\footnotetext{
${ }^{7}$ Data is provided by the Energy Information Administration
} 
western US between 1994-1996 for evidence of market integration. Their results show that markets were efficient and stable in that region. [9] compares the degree of competition between the electricity markets of England, Wales, Norway, and Australia. It concludes that the differences in the degree of competition level across international electricity markets can be explained by the differences in market design. [3] discusses the complex decisions faced by the generators in deciding how much to trade in the different California electricity markets (e.g. dayahead market, spot market, ancillary market, etc). It argues that rational behavior leads generators to continuously adjust their strategies to take advantage of the arbitrage opportunities across markets. [4] examines the evolution of the competitive electricity markets in California and PJM. It also proposes regulatory modifications that may make these two markets more competitive. [5] analyzes the advantages and disadvantages of binding and non-binding dayahead markets. [6] evaluates the level of market integration between the California day-ahead market and the real-time market. It concluded that the price convergence between these two markets increased as time passed.

This research contributes to previous empirical literature by evaluating the efficiency of the three major power markets in US (California, PJM, and New York). It computes a measure of market efficiency for each market for each of the years analyzed. It also compares the efficiency across different time markets and across states.

\subsection{The model}

Market efficiency can be evaluated by the "predictability" of changes in the price. In an efficient market, one should not be able to make abnormal economic profits using readily available information. The current price should reflect all the relevant and ascertainable 
information. Predictable prices imply that generators could use readily available information to design strategies that yield abnormal profits. This study performs two tests: First evaluates the "predictability" of a price series by testing its "stationarity". A series $Y_{t}$ is said to follow a stationary process if its mean, variance and autocorrelation are independent of time, implying that one could calculate the future values of a series using its current values. Two, it looks for arbitrage opportunities by checking if the expected return in the forward and the real markets are the same using cointegration analysis. Two series are cointegrated if they have a common trend and change roughly at the same rate. If the day-ahead and the real-time markets are cointegrated, a shock in the former will also be reflected in the latter and the expected return in both markets will be the same. This would imply that generators can not play across markets to increase their profits.

From the definition of an efficient market it should be clear that the price series of an efficient market can not be stationary. Otherwise, it would be possible to use the past information to predict the future changes in prices and make abnormal profits. Also, the forward and realtime prices should be cointegrated for the market to be efficient, otherwise the difference in expected returns would create arbitrage opportunities and cause inefficiency. To test the stationarity of a series, we check for the presence of a unit root in the price series using the Augmented Dickey-Fuller (ADF) test [10]. The ADF test requires the estimation of the following regression equation:

$$
\Delta P_{t}=\alpha+\beta_{0} P_{t-1}+\sum_{l=1}^{L} \beta_{l} \Delta P_{t-l}+e_{t}
$$

Where: 


$$
\begin{array}{ll}
\Delta \mathrm{P} & =\text { Change in the electricity price } \\
\alpha, \beta_{0}, \beta_{1} & =\text { Coefficients } \\
\mathrm{P}_{\mathrm{t}-1} & =\text { Electricity price in period } \mathrm{t}-1 \\
\mathrm{e}_{\mathrm{t}} & =\text { Residuals }
\end{array}
$$

The null hypothesis of this test is $\beta_{0}=0$. The number of lags in equation (1) was determined by initially estimating a general model with 15 lags and then in successive estimations the insignificant lags were dropped. This procedure makes sure that the results of the ADF test are not misleading and the residuals in (1) are uncorrelated.

As was mentioned in the earlier discussion of market efficiency, the expected return in the day-ahead and real-time markets for the same hour should grow at the same rate. Note, that both markets trade the same commodity. If the expected return in one market is more than the other, there would be an opportunity to make risk less profit and the market would be inefficient. In time series analysis, if two series track one another and grow roughly at the same rate, they are said to be cointegrated. By definition, cointegration necessitates that the two series be integrated of the same order and have a common trend. The order of integration is the number of times a non-stationary series has to be differentiated to obtain a stationary series. Two series with different order of integration cannot be cointegrated. An important consequence of cointegration is that it is possible to find a linear combination of the cointegrated series that generates a stationary series. This property is used in testing for cointegration. The following cointegration relation was tested here:

$$
P_{d, h}=\alpha+\beta * P_{r, h}+\varepsilon_{h}
$$

Where:

$\mathrm{P}_{\mathrm{d}, \mathrm{h}} \quad=$ Price of the day-ahead market at hour $\mathrm{h}$ 
$\mathrm{P}_{\mathrm{r}, \mathrm{h}} \quad=$ Price of the real-time market at hour $\mathrm{h}$

$\alpha, \beta \quad=$ Parameters of the cointegration vector

$\varepsilon_{\mathrm{h}} \quad=$ Error

This paper uses the Johansen test to determine the cointegration between the day-ahead and real-time market for each hour. The application of the Johansen test requires the estimation of a Vector Autoregressive model (VAR) of the form:

$$
P_{t}=\Gamma_{0}+\Gamma_{1} P_{t-1}+\Gamma_{2} P_{t-2}+\ldots+\Gamma_{k} P_{t-k}+\varepsilon_{t-k}
$$

Where

$\mathrm{P}_{\mathrm{t}} \quad=$ Column vector with the day-ahead and real-time prices

$\Gamma_{\mathrm{i}} \quad=$ Matrix of parameters

$\varepsilon . \quad=$ Disturbance

The number of lags in the estimated VAR model was determined using the Schwarz information criterium (See [11]). Under cointegration the matrices of parameters in (3) should be short ranked. The Johansen test uses this property to test for cointegration. See [12] for details.

Based on the results of the unit roots and cointegration tests, a measure of efficiency for each year and state market was constructed in the following way:

$$
E_{i, j}=\frac{C h_{i, j}}{24} * 100
$$

Where:

$\mathrm{E}_{\mathrm{i}, \mathrm{j}} \quad=$ Efficiency of market $\mathrm{i}$. in year $\mathrm{j}$.

$\mathrm{Ch}_{\mathrm{i}, \mathrm{j}} \quad=$ Number of cointegrated hours of market $\mathrm{i}$. in year $\mathrm{j}$. 


\section{Results and discussion}

Table 1 shows the unit root test results for each hour in a year, in California, PJM, and New York. From Table 1 it can be observed that in all the three states, some hours were stationary. In California the number of stationary hours rose between 1998 and 1999 but then dropped in 2000 in both the day-ahead and real-time markets. The increase in inefficiency between 1998 and 1999 could have been due to the significantly higher wholesale prices and artificially set price caps. These price caps had not been triggered in 1998.

For PJM, the real-time market was very inefficient in 1999 (71\% of the real-time market hours were stationary). The number of stationary real-time market hours dropped significantly in 2000 and 2001. This could be due to the fact that PJM switched to multi-settlement system in 2000 from a single-settlement system. In a multi-settlement system the forward commitments are binding and most of the trading occurs in the forward markets.

The real-time market was quite inefficient in N.Y $(50 \%$ of the real-time market hours were stationary) during 2000 and 2001 . However, the day-ahead market was efficient in more than $95 \%$ of the hours. This difference in efficiency between the two markets may be explained by the fact that most of the volume is traded in the forward markets. The real time market only operates like an imbalance market with very little volume compared to the forward markets. When the market has few players, low volume, lack of information flow due to time constraints, it is likely to be more inefficient.

Table 2 shows the efficiency results as measured by the cointegration tests. In California the forward and real time markets were cointegrated $63 \%$ of the hours in 1998 which increased to $83 \%$ in 2000 . This improvement may be explained by a "learning by doing" process as players learn from their past experience and exploit all the arbitrage opportunities available in the 
market, ultimately making the market more efficient. In PJM, there was no significant change in the number of cointegrated hours between 2000 and 2001. Comparing California and PJM in year 2000, it is noteworthy that California was slightly more efficient than PJM. In fact California had the highest level of efficiency among the three markets. In New York the market efficiency measure stayed at 50\% in 2000 and 2001. The lack of "learning" in New York between 2000 and 2001 may be explained by the existence of barriers and transaction costs that stopped traders from taking advantage of the arbitrage opportunities or by high levels of risk aversion among players (See [6]).

In 2000 the electricity prices in California and New York skyrocketed, whereas in PJM they remained stable. Interestingly, in 2000 there was no difference in market efficiency between California and PJM, suggesting that the differences in price behavior between these two markets were not due to market efficiency. Thus, other potential explanations (e.g. market power, supply constraints) should be explored to understand the differences in price dynamics between California and PJM power markets in 2000. On the other hand, New York market was significantly more inefficient than PJM in 2000 and 2001. Perhaps, market efficiency could explain differences in price behavior between PJM and New York. An efficiency ranking of the three state electricity market renders California as the most efficient and New York as the least efficient for year 2000 .

\section{Conclusions}

This paper evaluates the efficiency of the power markets in California, PJM, and New York for the past few years. Several conclusions can be derived from our results. First, in both 
California and PJM, the efficiency of the power markets has improved with the maturity of the markets. Second, multi-settlement scheduling system seems to be associated with higher market efficiency. Third, contrary to the common belief, in 2000 the California market appears to be as efficient as the PJM market based on our measure. Thus, the differences in price dynamics between these two markets can not be explained by the differences in efficiency. However, an efficiency argument may be made to explain differences in prices between NY and PJM in that year.

\section{Further research}

Further research on the following topics could be explored: First, a cointegration analysis between the ancillary services markets, the forward, and the spot markets could be implemented using the same methodology discussed here. Second, a cointegration analysis could also be implemented in testing for price convergence across the different scheduling coordinators in California. Finally, other potential explanations that clarify the difference in price behavior of different markets could be explored more rigorously.

\section{References}

[1] Borenstein, S. 2001. The Trouble with Electricity Markets (and some solutions). University of California. Energy Institute. PWP-081.

[2] Fama, E.F., 1970. Efficient Capital Markets: A Review of Theory and Empirical Work. Journal of Finance. 25:383-417.

[3] Quan, N., and Michaels, R. 2001. Games or Opportunities: Bidding in the California Markets. The Electricity Journal. 1040-6190/01. 
[4] Kench, B. 2000. The Process of Making "Competitive" Electric Power Markets in California and PJM. Working Paper. The University of Connecticut.

[5] Cameron, L., and Cramton, P. 1999. The Role of the ISO in US Electricity Markets: A Review of Restructuring in California and PJM. The Electricity Journal. 1040-6190/99.

[6] Borenstein, S., Bushnell, J., Knittel, C., and Wolfram, C. 2001. Death of a Market: Trading Inefficiencies in California's Electricity Markets. Mimeo. Boston University.

[7] De Vany, A.S., and Wall,W.D. 1999. Price Dynamics in a Network of Decentralized Power Markets. Journal of Regulatory Economics. 15:123-140.

[8] De Vany, A.S., and Wall,W.D. 1999. Cointegration Analysis of Spot Electricity Prices: Insights on Transmission Efficiency in the Western US. 21:453-448.

[9] Von der Fehr, N.H., and Harbord, D. 1998. Competition in Electricity Spot Markets. Economic Theory and International Experience. Working Paper. Oslo- Department of Economics.

[10] Dickey, D.A., and Fuller, W.A., 1979. Distribution of the Estimators of Autoregressive Time Series with a Unit Root. Journal of the American Statistical Association. 7:391-395.

[11] Grasa, A. (1989). Econometric Model Selection: A New Approach, Kluwer.

[12] Johansen, S., 1991. Estimation and Hypothesis Testing of Cointegration Vectors in Gaussian Vector Autoregressive Models. Econometrica. 59, 1551-1580. 


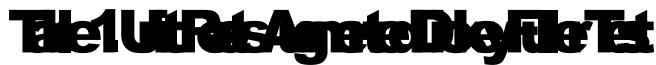

\begin{tabular}{|c|c|c|c|c|c|c|c|c|c|c|c|c|c|c|}
\hline \multirow[b]{3}{*}{ tos } & \multicolumn{6}{|c|}{ GFA } & \multicolumn{6}{|c|}{ PM } & \multicolumn{2}{|c|}{$\mathbf{M}$} \\
\hline & \multicolumn{2}{|c|}{108} & \multicolumn{2}{|c|}{10} & \multicolumn{2}{|r|}{20} & \multicolumn{2}{|c|}{0} & \multicolumn{2}{|c|}{30} & \multicolumn{2}{|c|}{201} & \multicolumn{2}{|c|}{ 2id } \\
\hline & Pa I & $d t a x$ & $d \mathbf{A}$ & Dyde & $\mathrm{dP}$ & Byda & $\mid \mathbf{R}$ & Bydex & $\mathbf{P A}^{\prime}$ & Bydax & $\mathbf{d} \mathbf{R}$ & Byda & $P A$ & Bydax \\
\hline 1 & 423 & $\sigma A$ & 1200 & 28 & $B 259$ & 00 & 520 & $M A$ & -180 & $\sigma A$ & 5200 & $3 k$ & -1120 & 26 \\
\hline 2 & 2203 & 24 & 2210 & 2 & $6-17 A$ & -11 & 220 & $\mathbf{M A}$ & 045 & 12 & 335 & 37 & $-11 \mathrm{SO}$ & $2 \pi$ \\
\hline 3 & -160 & $2 \pi$ & 2530 & 28 & $2-1 \pi 0$ & -18 & 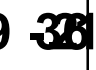 & $M$ & .04 & & 230 & 3 & 428 & 26 \\
\hline 4 & 2118 & -18 & (1) 330 & 20 & $9-160$ & -128 & 340 & $M$ & $\cos$ & $\omega_{0}$ & - ISR & & $6-12525$ & $2 \pi$ \\
\hline 5 & 20 & 265 & 2310 & 2 & (1) & -18 & 34 & $M$ & $0(2)$ & $0 a$ & 92 & $3 x$ & 30 & $22_{A}$ \\
\hline 6 & 202 & 24 & D) 200 & 24 & 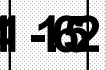 & $-13^{2}$ & 36 & $M$ & -120 & $O B$ & 1.614 & -18 & 33 & $-1 \mathrm{~A}$ \\
\hline 7 & 320 & $2 \pi$ & 228 & 260 & -125 & 0 & 30 & $M$ & -15 & $\boldsymbol{c o}$ & 420 & -11 & 2240 & -14 \\
\hline 8 & $21 B$ & 30 & 252 & $3 E$ & $3-130$ & -16 & 4.0 & $M$ & 0 & 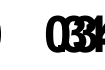 & $4-170$ & -11 & 268 & 2स \\
\hline 9 & -192 & 2 & 0250 & 3 & -138 & -15 & 36 & $M$ & $-16 \phi$ & $\infty$ & 2230 & -14 & 82213 & 20 \\
\hline D & -1765 & $x$ & $2 \pi 9$ & & $6-14$ & -15 & 350 & $\mathbf{M}$ & 20 & 0 & $2 \pi$ & -18 & 35 & 33 \\
\hline 11 & -1802 & 28 & 0287 & 28 & 226 & -188 & -1008 & $\mathbf{M}$ & $3 x$ & -15 & 22 & -100 & 40 & 32 \\
\hline R & 355 & 20 & 5278 & 20 & $52 \pi 0$ & 24 & 3-10485 & $\mathbf{M A}$ & 70.0 & 46 & $-7 x$ & -14 & 25 & $w_{4}$ \\
\hline$B$ & 249 & 34 & 330 & $2 \pi$ & 9200 & 23 & -100 & $M$ & 40.5 & 402 & 203 & $\infty$ & 230 & 305 \\
\hline 1 & 210 & 30 & 6395 & 28 & 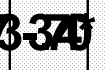 & $2 \pi$ & 53 & $M$ & 7.25 & 364 & 14 & 06 & 5.5160 & 480 \\
\hline 5 & $-(\mathbf{A D})$ & 28 & \$336 & 31 & 345 & 20 & 350 & $M$ & $2 \times$ & $3 \pi$ & $8.0 E$ & $\infty$ & 2330 & 31 \\
\hline 6 & -108 & 278 & $53 x$ & $3 K$ & 6208 & 20 & 6450 & $M$ & 28 & 210 & 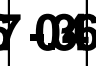 & & 5 & 260 \\
\hline$\nabla$ & -155 & 24 & 2405 & $3 k$ & 930 & 26 & 746 & $M$ & 30 & WE & 3.04 & OA & $-11 \pi 0^{\circ}$ & 2 \\
\hline B & -112 & 30 & .600 & $3 k$ & 3202 & 24 & $65: 5$ & $M A$ & -120 & 08 & 32 & -10 & 34 & 26 \\
\hline$\theta$ & -188 & उस & 229 & 68 & 243 & 25 & 2-10211 & $M$ & 085 & 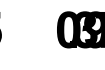 & 200 & $3 \mathrm{~B}$ & $5-1155$ & 24 \\
\hline $\boldsymbol{D}$ & 212 & $4 P$ & 201 & 63 & $5-189$ & 24 & 925 & $M$ & -152 & $\infty$ & 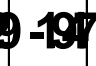 & -18 & 36 & $2 \pi$ \\
\hline $\boldsymbol{\chi}$ & 205 & $3 \mathbf{A B}$ & उस & 65 & $12 \mathrm{~min}$ & 23 & -1906 & $M$ & 34 & -12 & 389 & 220 & $8-1190$ & -16 \\
\hline $\mathbb{2}$ & -1007 & 234 & 6.266 & 28 & 0216 & 200 & -1.50 & $M$ & 28 & -18 & 3880 & & 2400 & -198 \\
\hline B & $-16 B$ & 24 & 2300 & 37 & 066 & 00 & 336 & $\mathbf{M A}$ & -132 & -10 & 200 & & $2-1120$ & 22 \\
\hline 2 & 200 & -14 & 7263 & 32 & 5060 & 0 & 600 & $\mathbf{M A}$ & 0033 & 15 & 8950 & 2 & 57.524 & -150 \\
\hline 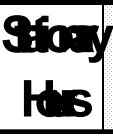 & & 4 & 6 & 5 & 2 & 0 & $\boldsymbol{\nabla}$ & $\mathbf{M A}$ & 3 & 4 & 3 & 2 & 2 & 1 \\
\hline
\end{tabular}

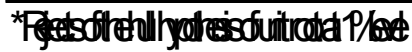

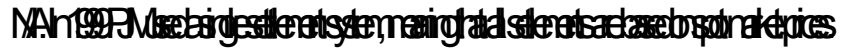


Table 2. Johansen Cointegration Tests

\begin{tabular}{|c|c|c|c|c|c|c|c|}
\hline & \multicolumn{3}{|c|}{ C ALIFOR N IA } & \multicolumn{2}{|c|}{ P J M } & \multicolumn{2}{|c|}{ N.Y } \\
\hline Hour & 1998 & 1999 & 2000 & 2000 & 2001 & 2000 & 2001 \\
\hline 1 & $x$ & 60.832 & 83.511 & $18.852^{*}$ & $\mathbf{X}$ & $\mathbf{x}$ & 67.777 \\
\hline 2 & 10.660 * & 60.077 & 31.963 & 29.132 & X & $x$ & 49.641 \\
\hline 3 & 8.770 * & 90.384 & 25.195 & 48.954 & 106.110 & 128.160 & 84.865 \\
\hline 4 & 45.105 & 165.370 & 47.360 & 69.346 & 112.250 & $\mathbf{x}$ & $\mathbf{X}$ \\
\hline 5 & 19.8 & 30.589 & 36.960 & 41.615 & 103.930 & 102.880 & 86.680 \\
\hline 6 & 42.026 & 35.650 & 20.982 & 35.568 & $\mathrm{X}$ & 112.980 & 86.050 \\
\hline 7 & 12.40 * & 26.300 & 14.165 * & 30.000 & 23.200 & 38.958 & 51.635 \\
\hline 8 & 82.28 & 29.260 & 18.140 * & 32.930 & $15.740^{*}$ & 67.062 & 52.440 \\
\hline 9 & 48.28 & $\mathrm{x}$ & 55.550 & 41.600 & 26.970 & 63.251 & 30.364 \\
\hline 10 & 44.047 & $x$ & 64.039 & 127.590 & 73.860 & 199.940 & $x$ \\
\hline 11 & 53.138 & 39.183 & 119.730 & 125.660 & 98.325 & X & 139.595 \\
\hline 12 & 67.984 & 57.719 & 142.410 & $x x$ & $\mathrm{X}$ & 227.270 & $x \times$ \\
\hline 13 & 25.4 & 98.128 & 135.730 & $x x$ & 86.930 & 214.870 & $x$ \\
\hline 14 & 29.97 & $x$ & $x$ & $\mathbf{X X}$ & 84.087 & $\mathbf{x x}$ & 138.290 \\
\hline 15 & 27.43 & $x$ & $x$ & 138.860 & 28.620 & 211.411 & X \\
\hline 16 & 23.76 & $x$ & 225.050 & 131.920 & 97.550 & X & $x$ \\
\hline 17 & 27.546 & $x$ & 46.852 & $\mathrm{X}$ & 81.480 & $x$ & 124.477 \\
\hline 18 & $x$ & $x x$ & 126.360 & 110.840 & 9.230 & 210.980 & x \\
\hline 19 & $x$ & $\mathbf{x}$ & 156.440 & 103.280 & 92.660 & x & $\mathbf{x}$ \\
\hline 20 & $x$ & $x$ & 29.610 & 85.155 & 83.810 & 201.807 & $x$ \\
\hline 21 & $x$ & $x$ & 123.580 & 110.890 & 113.890 & x & 101.730 \\
\hline 22 & 39.06 & 109.272 & 82.750 & 109.360 & $\mathrm{X}$ & $x$ & $x x$ \\
\hline 23 & 36.84 & 105.970 & 127.730 & 96.090 & 102.260 & $x$ & $x$ \\
\hline 24 & 9.750 * & 95.480 & 51.320 & 28.854 & $\mathrm{X}$ & $x$ & $x$ \\
\hline
\end{tabular}

\begin{tabular}{|c|c|c|c|c|c|c|c|}
\hline $\begin{array}{c}\text { Integrated } \\
\text { hour-markets }\end{array}$ & 15 & 14 & 20 & 19 & 17 & 12 & 12 \\
\hline Efficiency $\%)$ & 63 & 59 & 83 & 79 & 71 & 50 & 50 \\
\hline
\end{tabular}

${ }^{*}$ Cointegration hypothesis rejected at $5 \%$ level

$X$ stationarity in eiher day-ahead or real-time markets

XX stationarity in both day-ahead and real-time markets 